\title{
بلغاريا بين تثقيق الاصلاح السياسي والاستقرار في تطور الاصلاح الاقتصادي
}

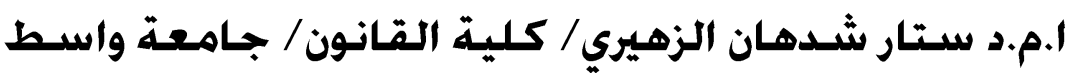

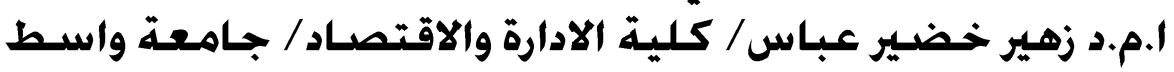

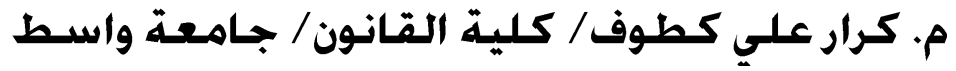

تأتي التحو لات السياسية والاقتصـادية في بلغاريـا بعد سلسـة من الاصـلاحات التـي شـهدتها في وسط وشـرق اوربـا اثر التغيرات التـي حصلت في الاتحساد السـوفيتي في عهد الثمانينـات مـن القرن الماضـي .امـا الظروف الصعبة التي شهدتها بلغاريا في فترة الحكم الثيوعي من ناحية غياب الديمقر اطية وانعدام المساواة في الحقوق و الحريات بين المو اطنين وغياب سيادة القانون فضـلا عن الظروف الاقتصـادية الصعبة التي شهـتها بلغاريا في ظل الحكم الثيوعي وتاثير ها على الحياة الاقتصادية للمواطن ـهذه الظروف الصعبة التي مرت بها بلغاريا دفعت الثعب البلغاري الىى المطالبـة بالمزيد من الحقوق و الحريـات وتتفيذ القانون واحتر امـة من قبل فيل السلطات الرسمية وكذلك تحقيق مزيد الانتعاش الاقتصادي و القضاء على الفقر و البطالة ـهذه الظروف دعمت من قبل الجهات الخارجية من الولايات المتحدة الامريكية و الدول الاوربيـة الغربيـة فكانت النتيجة التحول نحو

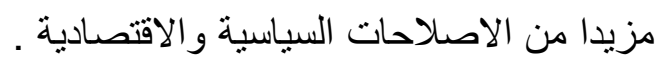

في بحثنا هذا سوف نوضح تلك الاصلاحات من خلال مبحثين رئيسين وهما: المبحث الاول :مرحلة بداية الاصلاحات السياسية والاقتصادية في بلغاريا المبحث الثاني :تطور مسار الاصلاحات السياسية والاقتصادية في بلغاريا مشكلة البحث: يو اجـه البحث عدة تسـاؤلات هي مـا طبيعـة الاصـلاحات السياسية و الاقتصـادية في بلغاريـا ومـا تأثثر هـا على الاوضـاع السياسية والاقتصـادية في بلغاريـا مـا تأثثير التحول نحو اقتصـاد السوق في الاقتصـاد البلغاري

فرضية البحث: تأتي الاصـلاحات السياسية والاقتصـادية تأثثير في بلغاريـا بعد الاصـلاحات التي شهـتها اوربـا الثرقية لذلك فان فرضيتنا هي ما تاثي الاصلاحات السياسية و الاقتصادية في بلغاريـا في مرحلة تحول النظام السياسي الى الديمقر اطية و الى التحول في نهج نظـام اقتصـادي قائم على اقتصـاد السوق و الحريـة الاقتصـادية

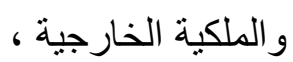

\section{المبـحث الاول- مرحلة بداية الاصسلاحسات السياسية والاقية والاقتصسادية في بلغـاريا :} تعد الاصلاحات السياسية والاقتصادية في بلغاريـا من اوليات الحكومـات المتعاقبـة في بلغاريـا والسير على نهج النظام الديمقر اطي و اقتصاد السوق لذلك سوف نركز على طبيعة الخصـائص التي تتميز بها بلغاريا من ناحية الموقع والموارد الطبيعية ومن ثم بداية مرحلة الاصلاح السياسي وبعده مرحلة الاصلاح الاقتصادي 


\section{المطلب الاول: طبيعة المنصائص التي تتميز بها بلغاريا}

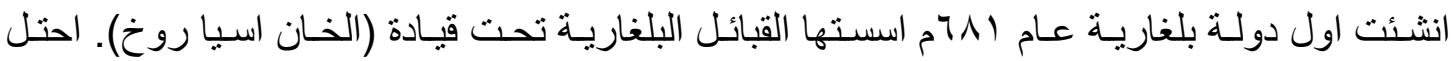
العثمانيون بلغاريا عام 97 ام ودام حكمهم اربع مئة سنة.حصلت على الاستقلال فعليا عام AVA ام .احتلتها القوات السوفيتية عام § 9 ام واعلن عن قيام الجمهوريـة البلغاريـة الثـعبية عام جـ 9 ام و واصبحت من الكتلة

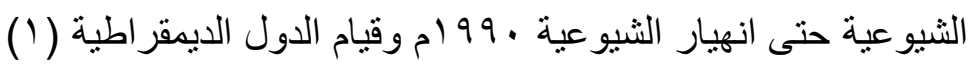

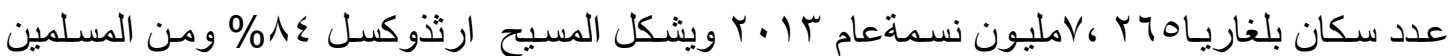
حوالي r ا \% ومسيحيون كاثوللك وطو ائف وديانات اخرى r \% (r) بلغاريا بلد صغير المساحة مساحتها • (9, • 1 اكيلو متر مربع تتميز بمناخ جيد وطبيعة جميلة من حيث وجود الجبال خضر اء والانهار و المياه المعدنية وشوطئ تمند على ضفاف البحر الاسود (r) بلغاريـا تحتـل جزء شـبه جزيـرة البلغـان الشـرقية على حدود خمسـة دول اليونـان وتركيـا من الجنوب ومقدونيا وصربيا من الغرب ورومانيا من الثمال تتكون بلغاريا حسب الهيكل الاداري بعد عام 1999 من VV مقاطعة ومن قطع تعتمد في ادارة النظـام المركزية في النظام الاقتصادي (ع) تتميز بلغاريا بالزر اعة من ناحية زر اعة المحاصيل الزر اعية وتربية الثروة الحيو انيـة وتربية الماثية

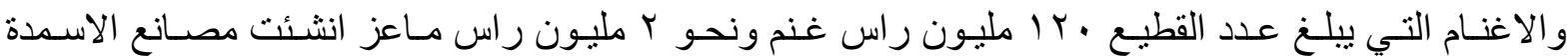
الكيمياوية وصناعة السيار ات والصناعات النسيجية وصناعة الموارد الغذائية(0)

\section{المطلب الثاني :التحول من النظام الشغمولي الى النظام الديمقراطي}

شـكلت العولمـة بانو اعهـا السياسـية و الاقتصــادية والاجتماعيـة وكانـت عمليـة التحـول نحـو النظــام الديمقراطي في بلغاريا .حيث مكنت شعوب ودول اوربا الثرقية في الاطلاع على الحياة في اوربـا الغربيـة من ناحية تطور مفهوم حقوق الانسان والحريات العامة ومبدا سيادة القانون فضلا عن تطور الحياة الاقتصـادية من ناحية الازدهار و التطور التكنولوجي والتقدم في العلوم و الصناعة مقابل تخلف واضـح في دول اوربـا الثـرقية ومنها بلغاريـا التي تعاني من انعدام حقوق الانسـان والحريـات العامـة في ظل الحكم الثيوعي وشيوع الفسـاد و البيروقر اطية وهيمنة الحزب الحاكم على كل مؤسسات الدولة (الحزب الثيوعي )(†) لذلك امام تلك التحديات لابد من دعم لعملية التحول نحو النظام الديمقرطي في بلغاريـا ـوقد وجد هذا الدعم من القوى المدنيـة المتمثلـة بـالمجتمع المدني و المنظمـات الغير حكوميـة في دول غرب اوربـا دورا

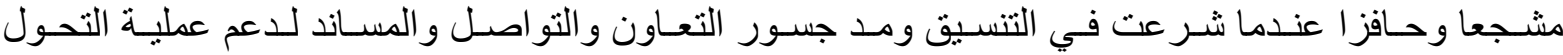

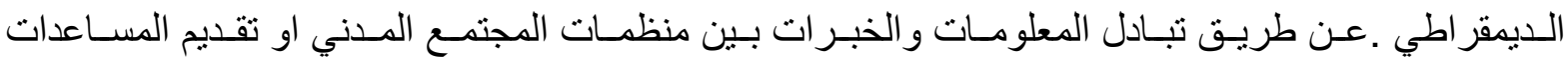
الاقتصـادية او شـن وسـائل الاعـلام الغربيـة لحمـلات الدعايـة المضــادة للحكم الثشيو عي وفضـح مـا ترتكبـه مـن انتهاكات لحقوق الانسان .يضاف الى ذلك الدعم المستمر من قبل اجهزة المخابرات الامريكية في التحريض 
ضد الثيوعية وتـاجيج الغضب الثـعبي على انظمتها الدكتاتوريـة .فضـلا عن الدعم والتأيد من الداخل حتى

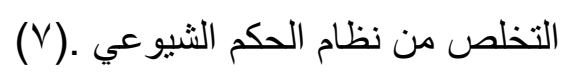

وفي سياق ذلك خرجت الاحتجاجات الثعبية المطالبة بالحريات وتحسين الاوضـاع الاقتصـادية وايجاد

حلول للمشاكل التي يعاني المو اطن البلغاري وقد واجهت السلطات البلغاريـة مزيدا من الضـغوطات من الداخل

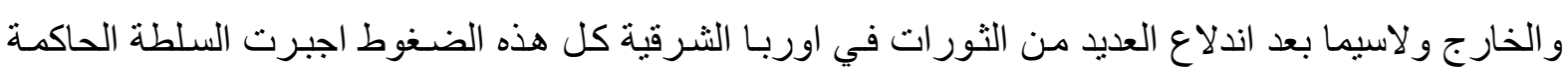

على مسايرة الاوضاع و القبول بالامر الواقع من ناحية التحول نحو النظام الديمقر اطي (^)

لم يحصل التغير بسر عة في بلغاريا فبرهنت الحركة المعارضة التي اطلقت على نفسها اسم تكتل القوى

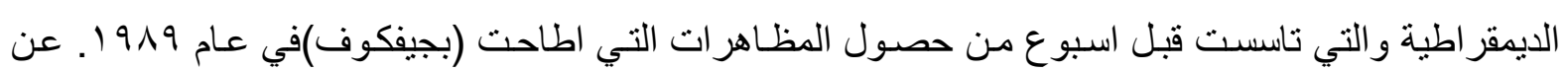

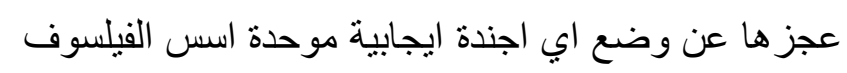

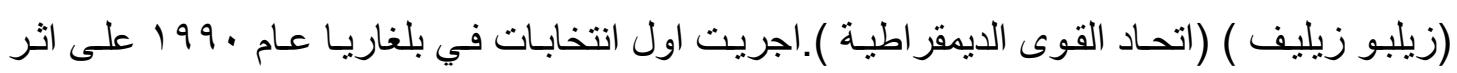

المفاوضات التي جرت بين الاشتر اكيين والمتحدين الجدد .قد فازو الاشتر اكيون في الانتخابـات بفضل التنظيم

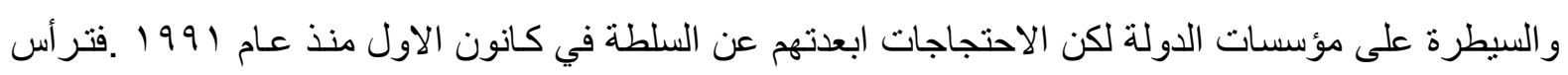
كتل التحالف القوى الديمقر اطية السلطة لكن فثل في تحقيق تو افق وطني ممـا اسفر عن ابعـاده من السلطة وتاليف حكومة اخصائيين ير أسها الاشتر اكيون عام بو 199 وقد كانت الاصـلاحات التي قامت بها الحكومـة من ناحيـة الاقتصـاد قد ارهقت كاهل المو اطن من انتار سلبية سـاهمت في عدم انتخـاب تيـار القوى الديمقر اطية

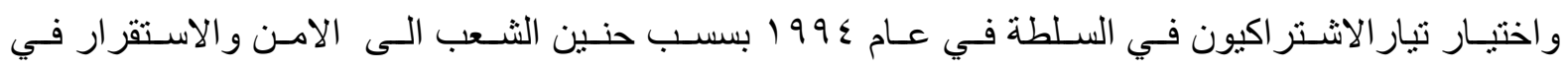

(9). (9)

لم تقوم السلطة الحاكمـة بالاصـلاحات المطلوبـة ولم يتم احتكـار السلطة مـن الحزب سـواء كان في

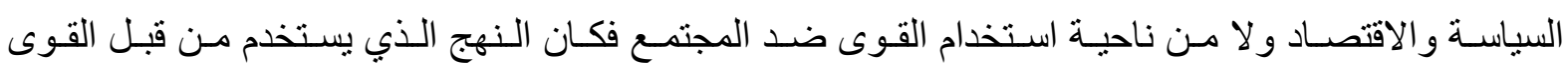
الاشتر اكية هو اسلوب الديمقر اطية في ادارة الدولة (· ( )

وقد اسفرت عملية التحول الديمقر اطي في بلغاريا بعد سلسلة مفاوضات بين القوى السياسية عن تبلور

نظام سياسي ديمقر اطي قائم على مبدا سيادة القانون.من حيث تشكيل ملامح النظام السياسي (1') __ صباغة الاطر الدستورية والقانونية الحاكمة ووضع دسنور جديد Y_تحديد بنية السلطة وطريقة توزيع السلطات و الفصل بينهما r ت_عديد بنية البرلمان (مجلس واحد او مجلسان ) ع_اختيار نظام انتخابي يقوم على التمثيل النسبي و المخرج بين النظامين o_تحديد الاختصاصات و الصلاحيات المنوطة لكل من الرئيس و البرلمان و القضاة 
وفي انتخابات عام 1997 فازت الاحزاب الاشتر اكية بالسلطة لكن الظروف الاقتصـادية الصعبة التي

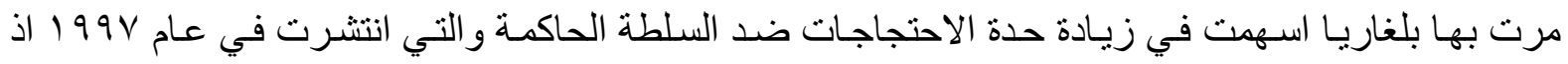
حاصر المتظاهرون البرلمان و النواب في محاولة لإجبار هم على حل المجلس التشريعي واجر اء انتخابـات وقد اقتنع الرئيس (بيتر ستوبانوف) بالتنازل عن و لايته لتشكيل حكومة جديدة تسهل اجر اء انتخابات (Y ( ) ومع حلول مو عد الانتخابـات عام | ... حدد الاشتر اكيون اهدافهم في الوصول الى السلطة وتعزيز نفوذهم من خلال تحقيق الانسجام والتفاهم بين القوى و الاحز اب الاشتر اكية و اصبح (يارفانوف)رئيس بلغاريا الذي حصل على الدعم من الاتحاد الاوربي ومن حلف شمال الاطلسي وقد اسس الملك (سيمون الثاني) حركة سيمون الثاني الوطنية التي الحقت الهزيمـة باتحـاد القوى الديمقر اطيـة بعد مـا وعد بتحقيق معجزة اقتصسادية ومحاربة الفساد (T) وفي انتخابـات ه . . ب كـانوا المـواطنين البلغـاريون على موعد مـن فرصـة للتعبيـر عن ارائهم في الانتخابات و هو يوم حساب (ساكسكويور غوتسكي) بسبب سياسـة التقشف التي تبناهـا في حكومتـة وهكذا فـاز

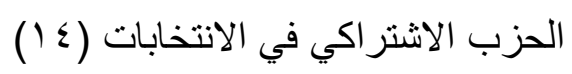

\section{المطلب الثالث: التحول من الاقتصساد الاشتراكي الى اقتصساد السـوق الحسر في بلغاريا}

يعد الاقتصاد البلغاري من الاقتصادات الصغيرة اذ يعتمد على الزر اعة والسياحة رغم توفر الخامـات المعدنية مثل الحديد والرصاص و النحاس لكنها تفتقر الى الخامات الطبيعية مثنل النفط و الغـاز لذلك عليها زيادة المحاو لات الاشتر اكية وهذ لان بعطي الى بلغاريـا توفير العملة الصعبة واثناء الحكم الثيو عي تمتعت بلغاريـا بمعدل نمو مرتفع جدا في السبعينات حيث كانت النسبة ^, ؟\% ثم تباطئت فيها بعد الثمانينات من القرن الماضي ولي

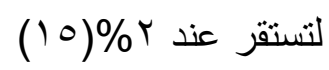

تبنت الاحز اب الحاكمة جملة من الاصلاحات الاقتصادية بعد التدهور الكبير في الاقتصساد البلغاري من

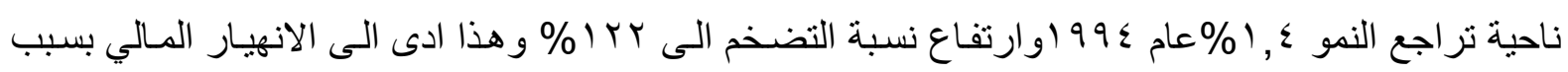

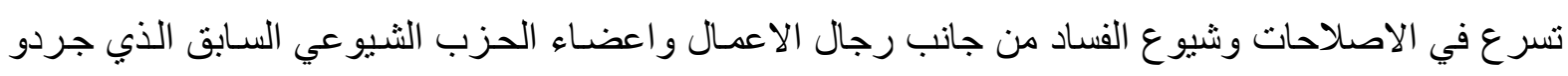

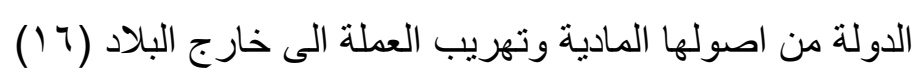

امام تلك التحديات لابد من الحكومة وضع خارطة اصلاح اقتصادية لانقاذ الاقتصـاد البلغاري الضعيف لذللك ادركت حكومـة القوى الوطنيـة الديمقر اطيـة تلك التحديات ممـا يترتب عليهـا وضـع سياسـات اقتصـادية لمعالجة تلك التحديات لذلك اتخذت جملة من السياسـات الاقتصـادية فاسست مجلس العملة مستقل يعني بتامين

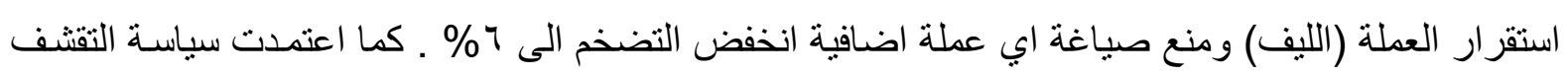
في الاقتصاد الكلي التي اوصى بها صندوق النقد الدولي و البنك الدولي وخفضت الاعانات المخصص للشركات الصناعية الكبيرة القديمة وخفض عجز الموازنه ووضعت قواعد ملزمة مصرفية وخاصة لسوق العمـلات. و وقد

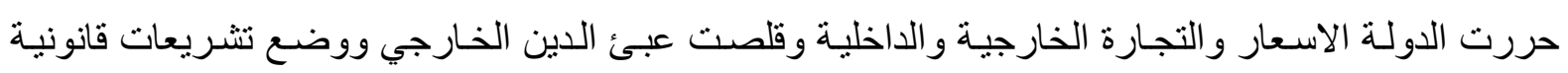
لانثاء سوق الارض فاعلة .قللت الانظمة العديدة وخفضت الضر ائب فاجبرت العديد الى الخروج عن اقتصـاد 
الظل و المشاركة في عائدات الدولة . اطلقت الحكومة عملية خصخصه مهمة وبحلول عام 999 اذ ارتفع نسبة المالكين من خارج اطار الدولة الى هب\% مقابل \% \% من اجمالي الناتج المحلي وفقا (لكسندر بوحكوف) نائب رئيس الوزراء والقوة السياسية الدافعة وراء تللك الاصلاحات اللبير الية (IV)

المؤشر ات الاقتصادية حول بلغاريا توكد مرحلة الانتعاش فمعدل الناتج المحلي الاجمالي لعام ...

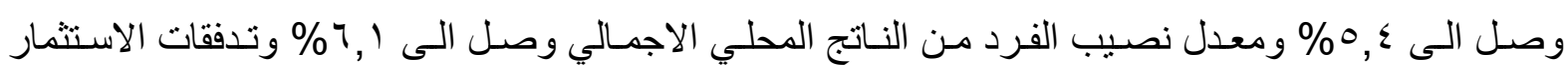

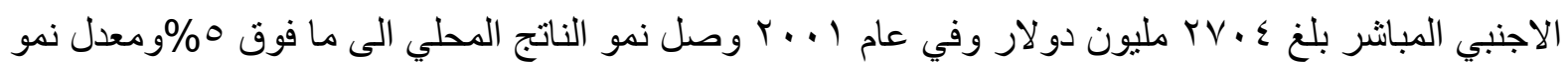

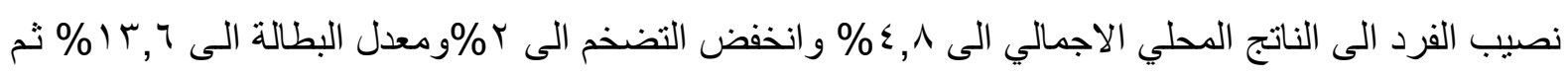

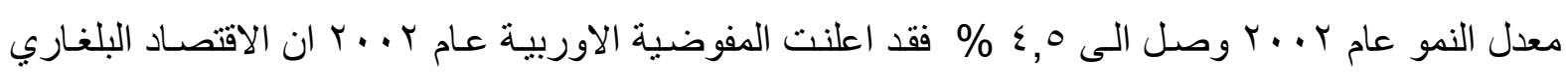

اقتصاد سوق (1) (1) (1)

\section{المبـحث الثاني :تطور مسـار الاصسلاحسات السياسية والاقتصسادية في بلغاريا}

في هذا البحث سوف نركز على الية تطور النظام الديمقر اطي في بلغاريـا من ناحيـة تنفيذ الاصـلاحات السياسية والخطوات التي اتخذت في تطوير الاقتصاد من ناحية تنفيذ الاصلاحات الاقتصادية في بلغاريا

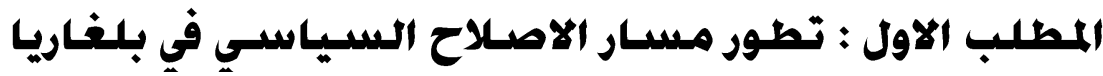

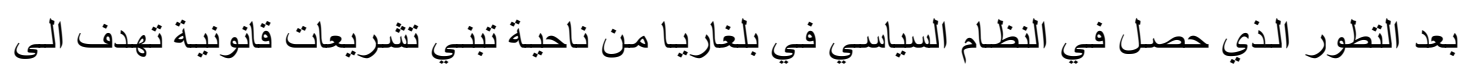

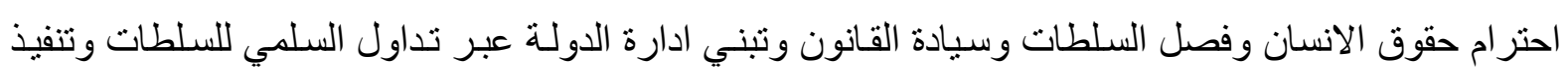

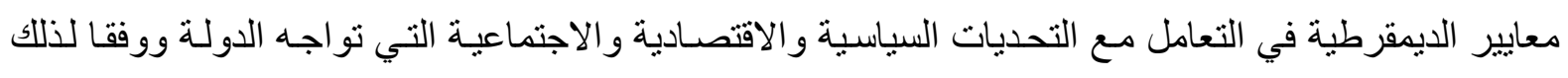
فكان الهدف هو الانضمام اللى الاتحاد الاوربي و الاستفادة من الدعم السياسـي و الاقتصـادي الذي يقدمـه الاتحساد الاوربي الى الدولة التي تريد الانضمام اليه في هذة المرحلة بدات الاصـلاحات الجديـة التي من شـانها مطابقة النظـام الاقتصـادي و الديمقر اطي والقـانوني مـع المعـيير الاوربيـة وقد شـر عت بلغاريـا في تصـنيف قو انينها

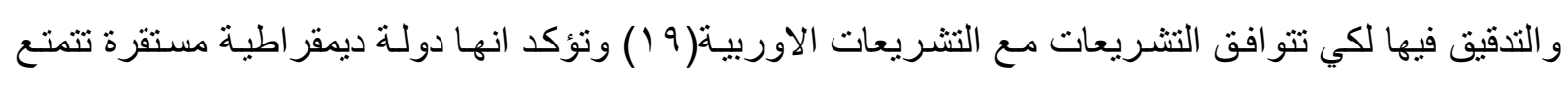

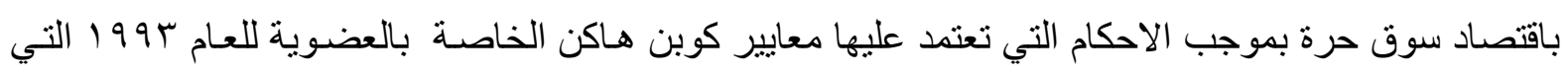

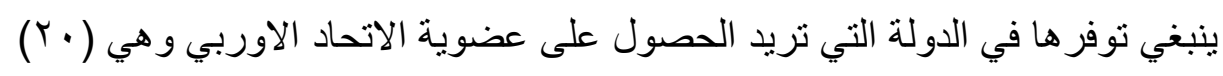
'_مؤوسسات مستقرة تضمن الديمقر اطية وحكم القانون وحقوق الانسان واحتر ام حقوق الاقليات

$$
\text { r_اقتصاد سوق فعال قادر على المنافسة في السوق الاوربية }
$$

بـ_الوفاء بالالنزامات العضوية في الاتحاد الاوربي في ما يخص الجوانب السياسية و الاقتصادية والمالية.

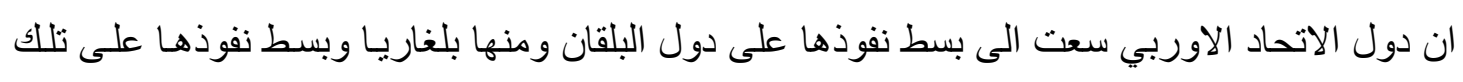
المنطقة وضمها الى مشروع اوربـا لضمان الموحدة لامتها والخالية من الصـر اعات السياسية الداخلية .والذي يعني عدم عودة النفوذ الروسي الى تللك المنطقة وعدم ترك الساحة الى فوى اخرى كي تحقق مصالحها الخاصـة بها التي قد تتعـارض مع مصـالح الاتحساد الاوربي حتئ لو كانت تلك القوئ حليفهـ لها مثثل الولايـاة المتحدة 
الامريكية ( (Y).وبعد سلسة من المفاوضات بين بلغاريا والاتحاد الاوربي الهدف منها هو تتفيذ معايير الاتحاد

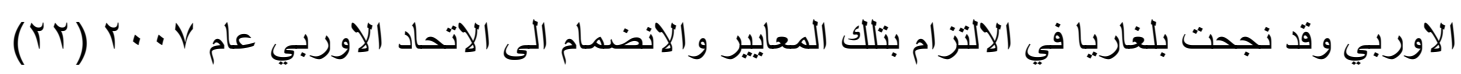

\section{المسطب الثاني: مسيرة الاصسلاح الاقتصسادي في بلغاريا}

سر عت بلغاريـا وتيرة الاصــاحات الاقتصـادية بهدف الاتضـمام الى الاتحساد الاوربـي وتتفيذ معـايير

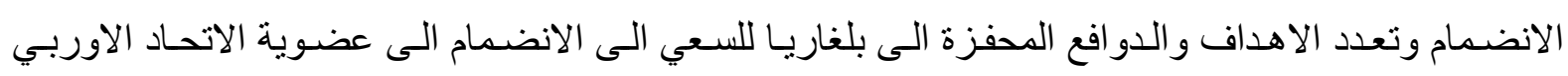

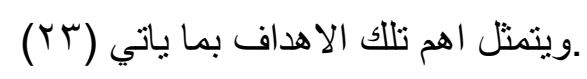

1_دخول السوق الاوربية الواسعة والاسواق الاخرى التي يرتبط بها الاتحاد باتفاقيات تجارية Y_التخلص من الحواجز الكمركية وغير الكمركية التي تعيق تدفق التجارة الى تلك الدول بـ_جذب الاستثمار الاجنبي المباثر والذي قد يسعئ الى جعل دول وسط وشرق قاعدة ينطلق منها الى السوق الاوربية الكبيرة

ع_الاستفادة من الحصول على مكان في اجزةة صنع القرار المهمة في الاتحساد الاوربي و المشـاركة في صنع

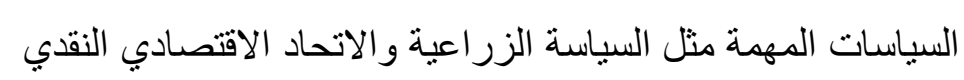

هـ_المفوضية الاوربية هي المتحدث الرسمي باسم الدول الاوربية ال(YV)في المفاوضـات الدولية المهــة مثل مفاوضات تحرير التجارة

وفي سياق ذلك شـر عت بلغاريـا في مكافحـة الفسـاد فأسسـة مبـادرة بالاشـتر اك مـع هيئـات ومنظمـات

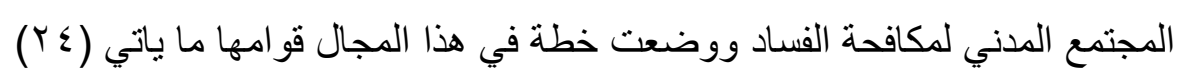
__اعلان بلغاريا دولة خالية من الفساد r-تفعيل المشاركة الثعبية والمر اقبة والاعلامية ع ـالجر اة والصر احة في تحديد المشكلات واليات حلها

هذه الاليـات التي نفذتها بلغاريـا سـاهمت في تحقيق الاوضـاع الاقتصـادية وتر اجع الفسـاد ـممـا شـع الاستثمار العـام على التوظيف والاستثمار الاجنبي على ارتفاعـه وز اد من اليـات وفعاليـة النمو الاقتصـادي

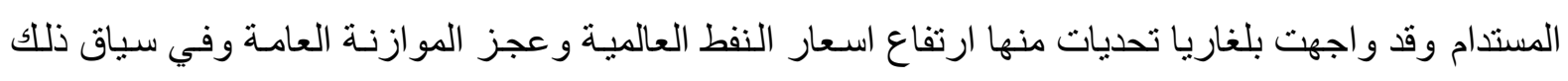
فقد استطاعت بلغاريا اتخاذ اجر اءت عديدة ساهمت في تطوير الاقتصاد البلغاري (Yo)وكان اهمها. اــاصـلاح النظـام التعليمسي من اجل مواكبـة شـروط رفع انتاجية العمل التي تعد هامـة في النمو الاقتصـادي المستدام r-تشجيع الثركات المتوسطة و الصغيرة واعدادها لاستيعاب برامج الدعم الاوربي ب-التحديث التكنولوجي و تغطيه المعايير المطلوبة 
ع-تعزيز وتطوير الحريه الاقتصادية و اليـة السلوك الاداري (البيروقر اطية) فبلغاريـا كانت تحتل المرتبه هوه في مؤشر الحرية الاقتصادية و وول ستريت جورنال هـتطوير المنـاطق الريفيه ورفع انتاجيـة القطاع الزراعي عبر تمويل المشـاريع و الانشطه الخاصـه بالقطاع الزراعي و الهدف الرئيسي هو معالجة مشكلة الفقر اصدرت بالغاريا عام 199 19 قانون الاستثمار الاجنبي و ثم انثاء مؤسسة تدير الاستثمار الاجنبي .وثم تحرير العملة المحليه عام 999 لكي تنفذ شروط صندوق النقد الدولي هذا القانون تشجع المستثمرين الاجانب على الاستثمار في بلغارياو الدخول في مشـاريع مشتركة و الاشتر اك في مناقصسات الخصخصـة في الاقتصـاد البلغاري .وساهم في تدفق الاستثمار الاجنبي الى بلغاريا .و على اثر ذلك تطور حجم الاستثمار الاجنبي بشكل

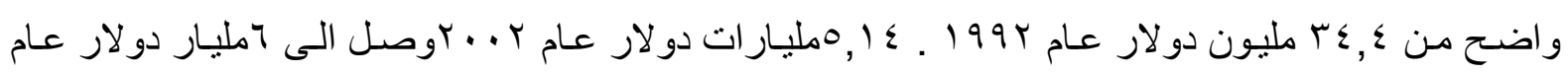

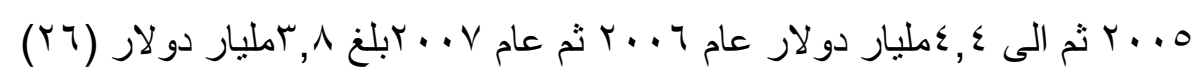
ولم يقتصر الامر على تدفقات الاستتمار الاجنبي المباثـر . بل هو الاثار الايجابية التي تترتب على جذب الاستثمار الاجنبي منل نقل المعرفة و التكنولوجياو زيـادة الصـادرات اي ان الدور الايجابي الذي سـاهم فيه الاستثمار الاجنبي هو اعـادة توجيه هيكل الصـادرات من سلع التي تعتمد على الموارد الخام و العمالـة و

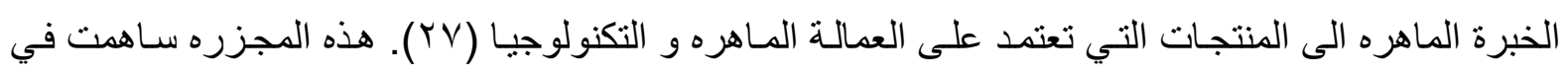

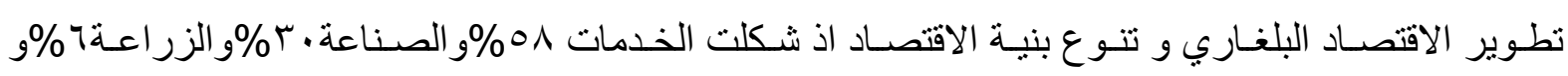
الغابـات ؟\% هذه الحالة انعكست على المستوى المعاثـي للمواطن البلغـاري حيث انخفض مستوى الفقر و البطالة (r^)

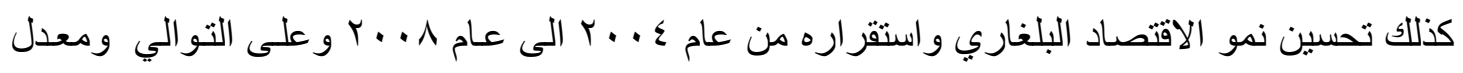

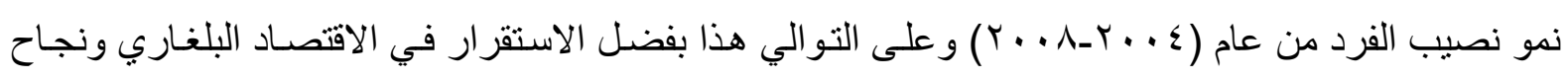

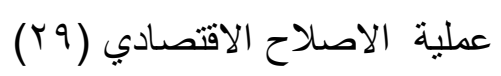
وقد تتوعت الصادرات لتشمل الاحذية و الملابس و المواد المعدنية و الصناعات الغذائية .وتعد كل من ايطاليا والمانيا و اليونان و روسيا اهم الثركات التجارية.اما واردات بلغاريا فكانت النفط و الغازو المنتوجات. هذه الحالة ساهمت في خفض الديون بمعدل • ب\%من الناتج المحلي (·r)

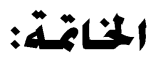

بعد البحث في تفاصيل البحث نستطيع ان نؤكد ان بلغاريـا بلد تحول من نظـام الثيو عي الى نظسام

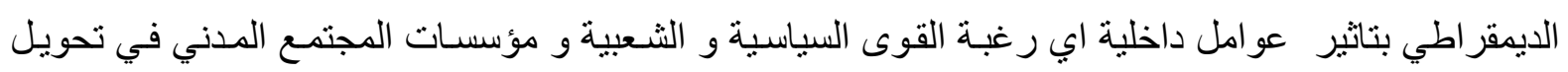
بلغاريا الى بلد ديمقر اطي يسود فيه مؤسسات دولة القانون و احتر ام حقوق الانسان . اما العامل الثاني فهو الخارجي متمثل بدعم المؤسسات الاوربية و الاعلام الغربي و مؤسسـات المجتمع المدني في الدول الاوربية الغربية للتخلص من النظام الثيوعي و ابعاد الدور الروسي من بلغاريـا ـ مـع سعي 
الثعب البلغاري الى التوجه نحو دول الاتحاد الاوربي بسبب الحالة الاقتصادية والمستوئ المعاثـي العـالي الذي يعيش فية المو اطن الاوربي مقارنة بالفقر و البطالة في بلغاريا ـ وقد اسهم هذا التحول في النضـام البلغاري في تشجيع الاتحاد الاوربي الذي وضع معايير الاصـلاح السياسي و الاقتصـادي مقابل الانضـمام اليهه و تقدم اللدعم

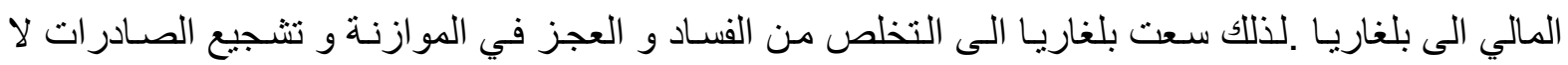
سيما الى دول الاتحاد الاوربي يفضل الانضمام اليه لذلك نستطيع ان نؤكد ان بلغاريـا رغم انها دولـة صغيرة و تنعدم فيها الموارد الطبيعية المهمة لكنها عوضت عن ذلك بواسطت القطاع الزر اعي و السياحة و الاستقرار السياسي لتحقيق الاهداف السياسية و الاقتصادية الى المجتمع البلغاري .

\section{المصادر و الهوامش بلش}

'_ _بلغاريا-ويكيديا-. الموسو عة الحرة .على الر ابط Hبلغاريا

r- بلغاريا .ويكيبديا .الموسوعة الحرة .المصدر نفسة

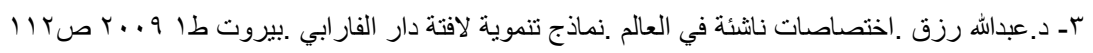

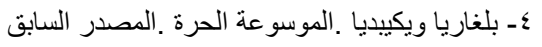

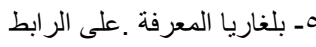

HTTPS;//AR.WIKIPEDIA.ORG/WIKIL

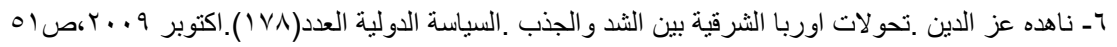

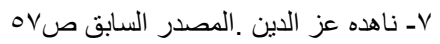

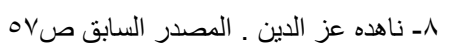

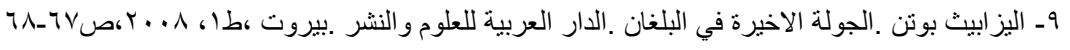

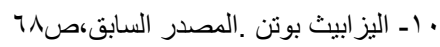
11

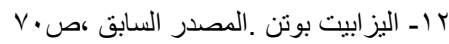

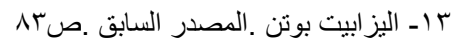

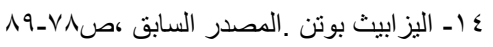

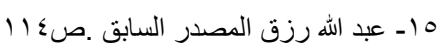

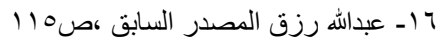

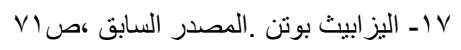

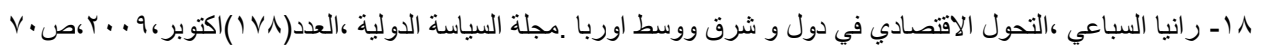

19 19

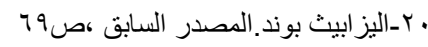

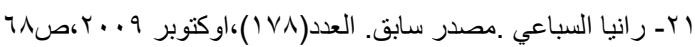

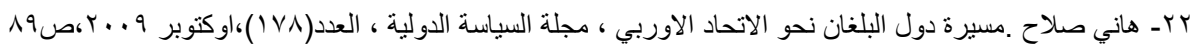

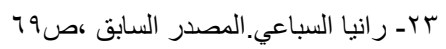

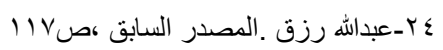

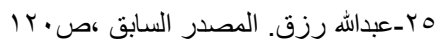

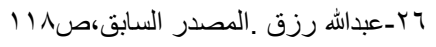
rV

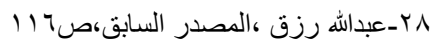

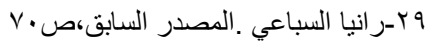

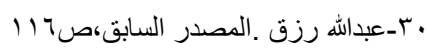

